\title{
SITC.N
}

\section{THE IMPACT OF SUSTAINABILITY ON DEVELOPING STRONG TOURISM BRANDS}

\author{
Milivoj Teodorović* \\ Singidunum Univirsity, Danijelova 32, Belgrade, Serbia
}

\begin{abstract}
:
The paper presents conceptual study on developing strong brands in tourism from the aspect of sustainability and consumer-based brand equity. The study shows significant opportunity for developing strong, favorable and unique brands in tourism if the elements of sustainability are included into the process of designing, building, measuring and managing brands.

Firstly, we present the overall review of concepts of sustainability, consumer-based brand equity and current tourism trends. Next, a conceptual diamond model is introduced for matching the major trends in tourism brands with dimensions of sustainability, consumer-based brand equity and consumer mind-set. Finally, an example of the city of Cardiff in Wales, United Kingdom, is analyzed and evaluated to further support the concept.

The overall significance of the model for the development of strong brands in tourism is presented from several different angles, which, nevertheless, offers significant view into the subject. The overall benefit of the study is in opening new horizons and identifying new opportunities in creating strong brands in tourism.
\end{abstract}

\section{Key words:}

consumer-based brand equity, sustainability, tourism, brand knowledge, ecological footprint.

\section{INTRODUCTION}

In this paper, we consider how the brands could and should be built using the synergy effect of tourism, sustainability and consumer-based brand equity. Also, we show that there is a significant opportunity for marketers in the tourism industry to create strong brands if sustainability maintained. A diamond model concept is used to show interconnecting relationships between tourism, sustainability and consumer-based brand equity.

The paramount of modern marketing is that brands never stand still. They constantly move and change. The tourism industry is not an exception. It constantly moves and evolves bringing new opportunities and challenges along. Marketers should keep this in mind when developing strong brands.

Creating and building strong brands is the ultimate goal of every marketer. Developing strong brands is the holy grail of marketing that brings substantial rewards to the companies, consumers, markets, industries and associated stakeholders. Brands have existed for centuries, however, only in the 80 s businesses started to look at brands from the value perspective. As a result, the concept of brand equity emerged. Our paper takes a view of the consumer-based brand equity (CBBE) as a differential effect that brand knowledge has on the consumer response (Keller, 2013, p. 68).

Sustainability as a concept formally emerged in the late $80 \mathrm{~s}$ as an outcome of the Brundtland report commissioned by the United Nations (Theis \& Tomkin, 2013). Other re- searchers (Huang \& Rust, 2011; Thogersen \& Crompton, 2009) suggest that sustainability is about managing limited resources. They think that resources should be more evenly distributed among the global population. In essence, the Brundtland report suggests that sustainability is a multi-faceted concept that in its basic form includes economy, society and environment. Later, the corporate world embraced this concept as the triple-bottom-line but, so far, fell short in enhancing the brand equity with it (Scharf et al., 2011, p. 79).

Tourism, as one of the biggest and fastest growing global industries, is home to many strong brands. Many of them are in airlines, hotels chains, countries, cities, team parks, national parks, resorts, events, and etc. At the global level one in eleven people works in tourism. Tourism accounts for $10 \%$ of the global GDP, grows globally by $3.5 \%$, which outpaces the global GDP growth of 2.4\% in 2014 (WTTC, 2014).

The study shows that future trends in the tourism industry, combined with the elements of sustainability, could play a significant role and present an enormous opportunity for marketers to build strong brands (Derouiche, 2012). The e-tourism, green or eco tourism, inbound-outbound, mission tourism and others combined with elements of sustainability are fertile ground for creating strong, favorable and unique brands.

The city of Cardiff, Wales, UK is a good example of how sustainability elements are analyzed and used to reinforce the brand equity of the city. The analysis of the ecological footprint shows how it impacts the environment and consequently the positive image of the city in the eyes of visitors. 


\section{BASIC CONCEPTS}

The rationale behind studying and proposing the model, where tourism, sustainability and brand equity interconnect, lays in the fact that these three domains have tremendous impact on one another. Tourism impacts environment, economy and society in many positive and negative ways. It creates jobs, boosts economy and increases a standard of living. However, on a negative side, it burdens environment, local culture, infrastructure and etc. Therefore, marketers should view tourism as a ground for creating new and reinforcing or revitalizing existing brands. Also, from the CBBE point of view, sustainability represents source for building strong, favorable and unique brands. Further analysis reviews each concept individually.

The role of branding: The power of marketing lies in creating brands. The power of brands lies in their brand equity or, from the consumers' point of view, in what the mind set holds about the brand. Brand equity is constantly reinforced by the meaning of the brand in terms of what products it represents, what core benefits it provides and what need it satisfies. Keller (2013, p. 68) describes the CBBE as a differential effect that brand knowledge has on the consumer response to the marketing programs and brand activities.

There are three major drivers behind the CBBE: the brand knowledge, differential effect and consumer response. However, the brand knowledge created by the past experience, marketing programs, word-of-mouth is responsible for customer perception about the brand. In other words, consumers' perceptions about a product are highly dependent on the impressions of the brand associated with the product (Keller, 2013, p. 71).

According to (Keller, 2013), brand knowledge is manifested via brand awareness and image. To build strong brands marketers must clarify brand awareness and improve brand image. Brand awareness is the ability to recall the brand and the probability that a brand will come to mind in certain situations. On the other hand, brand image refers to associations such as feelings, images, thoughts, impressions, perception, and experience that a consumer holds about the brand.

In order to maintain brands strategic trust and direction many tactical changes are needed. The key is to convey the message to consumers that the brand is a better product but not different. In managing brands over time, reinforcement and revitalization strategies are necessary. The key to reinforcement is consistency, while capturing the lost sources of brand equity is a first step for revitalization (Keller, 2013).

The importance of sustainability: The idea of developing strong brands without considering how environmentalfriendly they are and what impact they have on the society and the overall economy is a thing of the past. Obviously, a more holistic marketing approach, one that rapidly includes sustainability as a direction for future brand development, research and strategic activity, is needed.

Sustainability, as a concept, first appeared in the final report "Our Common Future" issued by the "The Brundtland Commission" in 1987 (Theis \& Tomkin, 2013). It was defined as "development that meets the needs of the present without compromising the ability of the future gen- erations to meet their own needs". The same report defines the three pillars of sustainability: social, economic and environment. The social represents "People" and its needs in terms of education, employment, healthcare, growth and the overall wellbeing. The economic or "Profit" is concerned with growth, profitability, market share, investment opportunities, markets and brands that satisfy the need of the "People". The third pillar, "Planet" is concerned with the environment. A more holistic approach suggests enhanced model with entrepreneurship, culture, innovation and etc. See (Fig. 1).

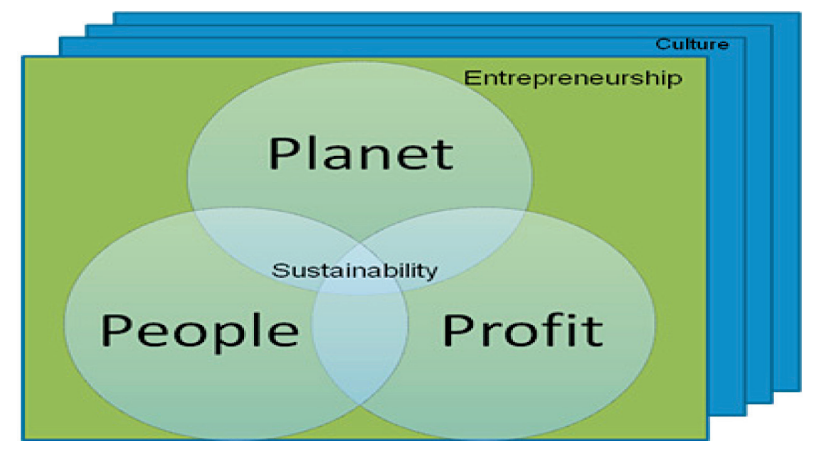

Figure 1: Holistic Sustainability Model

Planet resources are limited as is their capacity to regenerate them. Currently, humanity is using 1.5 Planet to satisfy its one year needs (WWF, 2014). Also, the same report shows that staggering forty percent of the animal populations were whipped out in the last forty years.

The changing tourism environment. In 2014, the global sector of the tourism industry (travel \& tourism) increased by $3.5 \%$, outpacing the global GDP growth of $2.4 \%$ according to (WTTC, 2014). E-tourism stands out among other trends as an example of mass customization that allows online trip booking and selection, bypassing the tour operators and standard travel packages. Other trends include new emerging inbound and outbound markets, sustainability tourism, mission tourism, climate change and alternative transport, social media, safety and security and workforce development.

New emerging inbound destinations in Eastern Europe, countries recently joining the EU, Asia and South America are arousing interest of many travelers. China and India, with over a billion people each, are emerging as outbound markets. With the increase in disposable income, China alone added 57 million travelers in 2010 (World Tourism Organization, 2015).

Sustainable tourism, also known as green or eco tourism is a rapidly growing branch of the tourism industry among those concerned with the negative effects that tourism can have on the environment. Weather patterns, natural disasters and the overall effects of the climate change may gradually become a significant factor in selecting travel and tourism destinations and options. Also, driven by the sustainability concerns, alternative means of travel, bicycle, scooters, bus, train, and short rather than long distances will become a factor in choosing travel destination.

Mission travel is gaining momentum with more and more tourists looking to add-value to their trip. Many opt 
to replace traditional 3S (sun, sand, sea) approach with active participation in the activities such as voluntary work, learning language, culture, concerts, local cuisine and various achievements.

Social media on the web-based applications and increasingly popular $\mathrm{m}$-applications allow global communication among individuals on their experiences. The technology is turning the table around. It matters less what businesses say about their products, but more what consumers say about them. Rapid dissemination of information makes the sharing experience and experiential marketing more visible and important in the tourism industry.

Finally, safety and security is of paramount importance for any tourist industry. People go only to the places and locations where they will feel safe and protected. Developing workforce is a never ending activity in tourism. It is the human element that creates a competitive advantage. Therefore, investments in human resources development will continue to receive a significant attention of stakeholders in the tourism industry.

\section{SUSTAINABLITY-BASED BRAND EQUITY CONCEPT}

Keller (2013, pp. 73-74) points that the CBBE occurs when the customer has a high level of knowledge and familiarity with the brand and holds strong, favorable and unique brand associations in his/her memory. The sustainability enhanced model is in fact the CBBE model wrapped into the individual layers of sustainability (Fig. 2). In the proposed model, the major brand knowledge elements such as breadth, depth, attributes and benefits are enhanced by environmental, social or economic features.

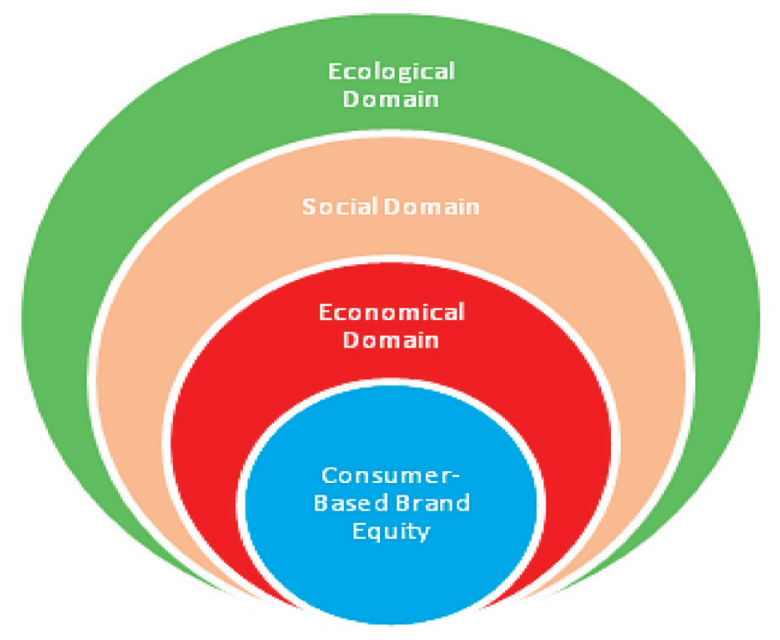

Figure 2: Sustainability Enhanced CBBE

The diamond model conveniently depicts the many-tomany relationship between the elements of sustainability and the $\mathrm{CBBE}$ in the tourism setting. It highlights the holistic relationship that takes into account many dimensions and views of sustainability and their impact on creating significant brand awareness via depth and breadth elements. Also, those sustainability elements must create strong, favorable and unique associations of the brand image, posi- tive reaction to the brand and clear nature of the relationship with the brand. The general diamond model captures the holistic nature of the relationship (See Fig 3). In order to look more closely into the model, we need to explore relationships between the individual elements of sustainability with the CBBE elements.

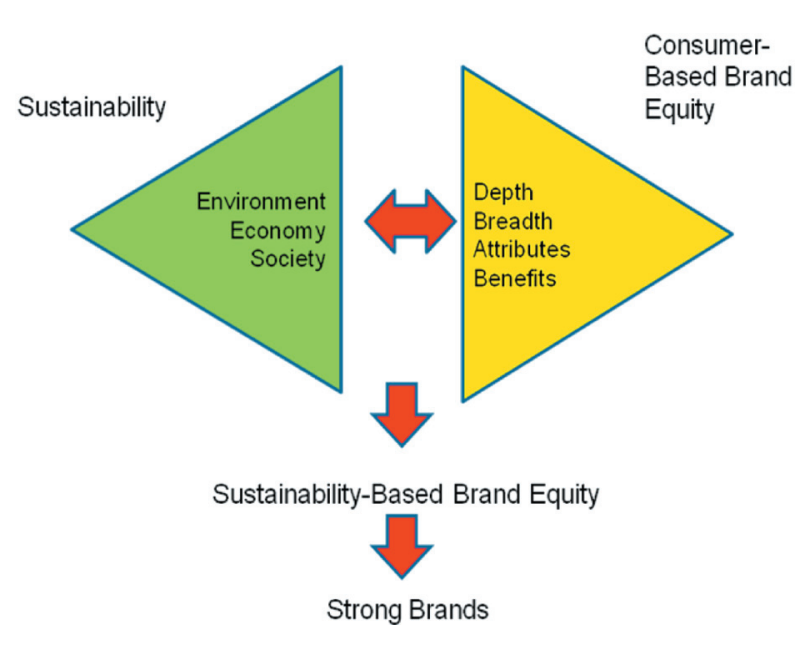

Figure 3: Sustainability-Based Brand Equity Holistic Model

Economic impact. The economic impact on the CBBE in the tourism industry depends in many cases on the nature and uniqueness of the individual tourism markets. However, a set of common guidelines is emerging, such as investing into the areas where business operates and returning the portion of the profit back to the local community, making contributions to preservation of the resources the brand is using, hiring local stuff and providing training, sourcing locally and supporting local community, tying the brand image to the local community, and practicing fair trade in the supply chain activity. See Fig 4.
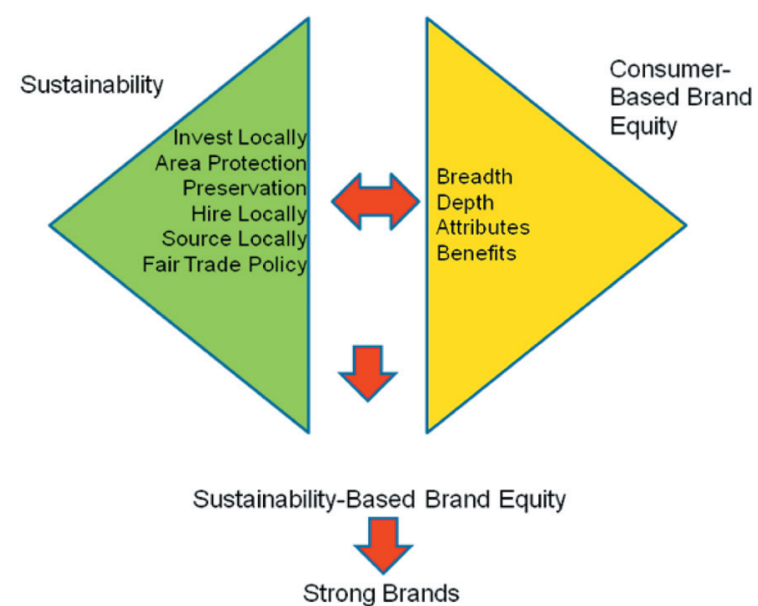

Figure 4: Economic Impact on CBBE

Social impact. The social impact on the CBBE in tourism is concerned with the preservation of the basic human rights, child labor, the overall wellbeing of the local community, preservation of endangered species, and respect for the local cultures and religions. See Fig 5. 


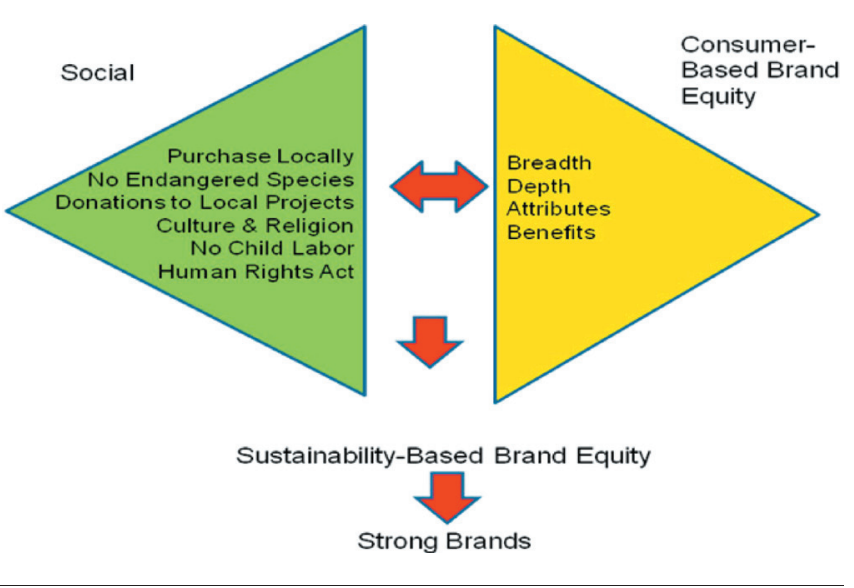

Figure 5: Social Impact on CBBE

Environmental impact. The environment is the most significant and challenging element to capture and implement into the CBBE. Strong tourism brands must take into account the responsibility for damaging environment, conservation and reduction measures, benchmarking environmental performance, incentives for preserving resources, environmental responsible practices such as waste management, green energy, organic food, lowering water footprint, innovations in reducing impact on the environment, tour sizes, $3 \mathrm{R}$ practice, and the overall incentive for preservation of resources at each contact point. The relationship is captured in Fig 6.

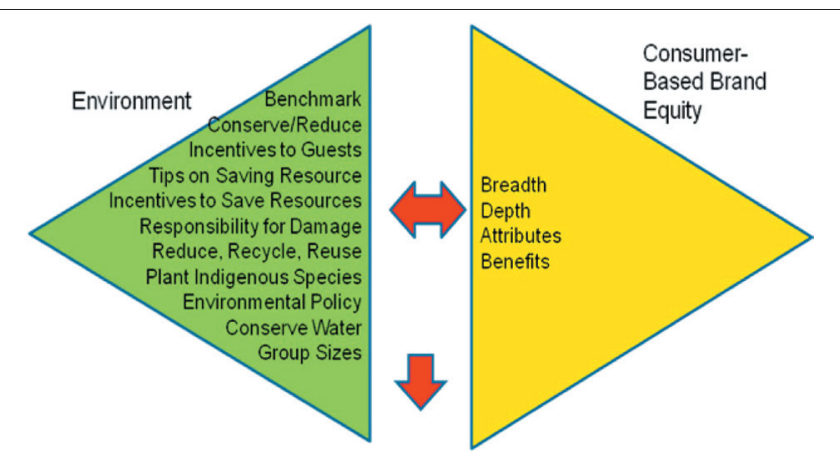

Sustainability-Based Brand Equity

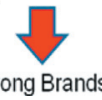

Figure 6: Environmental Impact on CBBE

\section{CARDIFF'S ECOLOGICAL FOOTPRINT}

In 2011, the office of national statistics shows that the city of Cardiff accounts for one quarter of $\$ 7$ billion revenue that Wales gets from tourism. According to (Collins et al., 2005) the city of Cardiff, just like many other cities in the developed world, lives beyond its means. The report reveals that consumption habits and effects are to blame. As a result, the ecological footprint was calculated for the city of Cardiff for two main reasons. Firstly, to measure the extent to which the residents of Cardiff impact the global environment, and secondly, to have a tool for managing and minimizing the impact. The objective of the study was to challenge citizens, organizations and households in Cardiff to come up with intelligent ways to use the resources to reduce the impact on the fragile environment. By doing so, the citizens of Cardiff can better plan their future by living more sustainably and in great balance with our one and the only planet Earth (Collins et al., 2005).

According to (WWF, 2014), Cardiff's per capita footprint is unsustainable 5.59 global hectares (gha). The same report shows footprints of 6 gha for London, 10 gha for the US, and 8 gha for India. The (WWF, 2014) shows that each person on the planet has on average 1.7 gha to go around. This means that citizens of Cardiff and most of the developed world live beyond its means imposing severe damage to the global resources. In other terms, if everybody on the Earth had the lifestyle of the people of Cardiff, we would need three planets to sustain our needs for one year.

The study shows that $78 \%$ of the Cardiff's footprint is related to the household consumption. The type of food, the way the heat and electricity are used, the type of travel, category of stores where people shop all ends up into the overall picture. The breakdown of the Cardiff's ecological footprint is shown in Fig. 7.

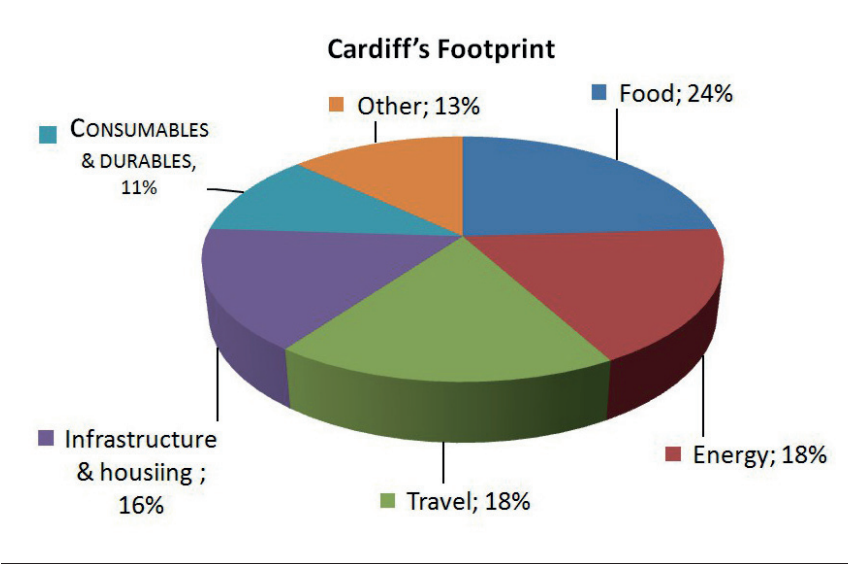

Figure 7: Cardiffs Footprint

Tourists bring large economic and social benefits to the city. Around 10 million tourists, 30\% from outside the UK, visit Cardiff each year. However, tourists carry a huge environmental burden in some cases up to 9 gha per individual. This is significantly higher than the average footprint of a Cardiff's resident of 5.59 gha. The tourist impact is heaviest in those areas where Cardiff's footprint is the highest: food and drinks, energy and transportation and waste. In 2001, on an aggregate level, the ecological footprint of tourists in Cardiff was higher than the footprint of its residents (Collins et al., 2005).

On the other hand, 10 million annual visitors spend at least $\$ 2$ billion, a substantial income to the city. Also, Cardiff is an important name on the travel map of many people. Significant level of the brand awareness and strong, favorable and unique associations that Cardiff holds are at stake if the footprint is not reduced. Tourist organizations, city officials and relevant stakeholders should work on reinforcing the consistency of what the city offers. In particular, they should work on improving the strength and favorability of what the tourists perceive as the city's major attractions. Consequently, the major associations or impressions of the city features need to be preserved and reinforced. Inevitably, the city must factor in its ecological footprint into the overall equation of its $\mathrm{CBBE}$. 


\section{SUMMARY}

As a result of this study, a local community is emerging as a way and direction for building strong sustainability enhanced brands in tourism. It seems that resources of the local community are the key in developing strong sustainable brands. Investing into the local human resources development, using local produce, stimulating local economy, recycling waste and utilizing short travel distances all favors back-to-the-local community concept.

The diamond model shows the complexity and direction that marketers are facing when incorporating the elements of sustainability in the CBBE. Marketers can choose among economic, social and environmental elements in its effort to flash down the strategy for new brands in tourism or reinforce and revitalize the existing ones. The key is to provide optimal many-to-many relations with the elements of the CBBE such as depth, breadth, attributes and benefits. The result is creation of strong, favorable and unique associations, with positive response and clear relationship with consumers.

The city of Cardiff is an example of how the strong brand equity of the city needs to be reinforced with the elements of sustainability. Unsustainable footprint of the city of Cardiff is threatening to deteriorate the strong brand equity the city enjoys in tourism.

This study, at least at the conceptual level, shows great opportunity for building strong brands in tourism, when local factor combined with sustainability elements is included. Also, this study opens the door and provides guidelines for more exploratory research and analysis in the field.

\section{REFERENCES}

Collins, A.J., Flynn, A., \& Netherwood, A. (2005). Reducing Cardiff's ecological footprint: A resource accounting tool for consumption. Cardiff: WWF Cymru.

Conrady, R., \& Buck, M. (2010). Trends and Issues in Global Tourism 2010. Heidelrberg: Springer.

Derouiche, M. (2012). The Future Trends in the Tourism Industry. Retrieved May 9, 2015, from http://www.ttgmena.com/Future-trends-in-the-tourism-industry/

Duval, D.T. (2004). Tourism in the Caribbean. London: Routledge.

European Travel Commission. (2014). European Tourism 2014 - Trends and Prospects. Retrieved May 9, 2015, from http://etc-corporate.org/?page=report\&report_ $\mathrm{id}=57 \&$ subject $=$ trends_watch $\&$ theme $=$ reports
Huang, M.H., \& Rust, R.T. (2011). Sustainability and consumption. Journal of the Academy of Marketing Science, 39 (1), 40-54. doi: 10.1007/s11747-010-0193-6

Keller, K.L. (2009). Building Strong Brands in a Modern Marketing Communications Environment. Journal of Marketing Communications, 15 (2-3), 139-155. doi: 10.1080/13527260902757530.

Keller, K.L. (2013). Strategic Brand Management. Essex: Pearson.

Kotler, P., \& Keller, K.L. (2012). Marketing Management. New York: Prentice Hall.

Scharf, E.R., \& Cunha, H.C. (2011). Mindful Consumption as Marketing Competitive Advantage: The Strength of Ideology Toward Purchasing Decision. The Sustainable Global Marketplace, (pp.77-81). doi: 10.1007/978-3-31910873-5_45

Theis, T., \& Tomkin, J. (2013). Sustainability: A comprehensive foundation. Houston, TX: Connexions. Retrieved February 12, 2015, from http://cnx.org/content/ col11325/1.38/

Thogersen, J., \& Crompton, T. (2009). Simple and painless? The limitations of spillover in environmental campaigning. Journal of Consumer Policy, 32 (2), 141-163. doi: 10.1007/s10603-009-9101-1.

Wales Online. (2014). Tourism worth $£ 4.2 b n$ to Wales with Cardiff accounting for one quarter of total, new figures show. Retrieved May 9, 2015, from http://www.walesonline.co.uk/news/wales-news/tourism-worth-42bnwales-cardiff-1806919

World Tourism Organization. (2015). UNWTO Tourism Highlights: 2015 Edition. Madrid: UNWTO. Retrieved May 9, 2015, from http://www.e-unwto.org/doi/ pdf/10.18111/9789284416899

World Tourism Organization. (2015). UNWTO Annual Report 2014. Madrid: UNWTO. Retrieved May 9, 2015, from http://dtxtq4w60xqpw.cloudfront.net/sites/all/files/ pdf/unwto_annual_report_2014.pdf

World Travel \& Tourism Council. (2014). Economic Impact of Travel and Tourism 2015 Annual Update Summary. Retrieved May 9, 2015, from http://www.wttc.org/-/ media/files/reports/economic\%20impact\%20research/ economic\%20impact\%202015\%20summary_web.pdf

WWF International. (2014). Living Planet Report 2014. Gland: WWF International. Retrieved May 9, 2015, from http:// www.wwf.org.uk/about_wwf/other_publications/living planet_report_2014/\#.VgD5z328vcs 